SHS Web of Conferences 6, 04002 (2014)

DOI: $10.1051 /$ shsconf / 20140604002

(C) Owned by the authors, published by EDP Sciences, 2014

\title{
An Empirical Research on Returns to Education of Disabled People during the Process of Modernization
}

\author{
Liao Juan ${ }^{\mathrm{a}}$ \\ School of Management, Capital Normal University, 100089 Beijing, China
}

\begin{abstract}
Education is one of the most important ways to form human capital. Individual can get profit from investment in human capital. Although education situation of the disabled is getting better slowly during the process of modernization, the study of return to education of disabled has been largely ignored for many years. Furthermore, there are still a number of challenges need to pay more attention. This paper based on CHNS data in the economic transition period using Mincer Equation to study the returns to education in the disabled people in China. The results show that the education level has significant positive relationship with the rate of return to education; Return to education of the disabled is lower than non-disabled and male higher than female. The paper suggested more special education supply are required, female disabled people should be pay more attention especially on their education.
\end{abstract}

Keywords. disabled; non-disabled; return to education; wage equation

\section{Introduction}

Persons with a disability are likely to have limited opportunities to earn income and often have increased medical expenses. According to the 2010 China sixth national census data, there are 85.02 million disabled population in China[1]. Unfortunately their status is often careless from public, and lack of relevant research. For persons with disabilities, education can contribute to get a job and integrate into the society. Therefore, education is not only to increase their income, but also plays a very important role in improving the quality of live and realizing themselves. If the rates of returns to education are high, it might be argued that there is an underinvestment in education of the disabled. If the rates are low, expanding human capital intervention as a way to improve employment or earnings may not be indicated [2]. Some existing literature estimate that the returns to education for the disabled and nondisabled, people with different type of disabilities[3][4]. In China, enormous literature exist in the study of the returns to education in recent years, which including urban residents' rate of returns to education [5], rural residents' returns to education [6] as well as returns to education of special groups, such as minority [7]. However, more than 80 million disabilities have not yet been studied. The purpose of this paper is to fill this gap by focusing on the role of education and estimate the rate of returns to education in disabled people.

The rest of this paper is organized as follows: section 2 shows the method to estimate the rate of returns to education of individuals with disabilities. The data set is described in section 3 , and

\footnotetext{
${ }^{a}$ Corresponding author: liaojuan2008@aliyun.com
} 
followed by a presentation of the empirical results are discussed. Finally, we conclude with findings and recommendations, as well as limitation of our research.

\section{Method}

Mincer (1974) equation [8] (also called standard human capital wage equation) is used in this study. Simple Mincer equation only includes two independent variables: schooling years and experience. The equation usually specified as follows:

$$
\ln (\text { wage })=\beta_{0}+\beta_{1} e d u+\beta_{2} \exp +\beta_{3}(\exp )^{2}+\varepsilon
$$

Where edu is schooling year, exp is a person's working experience and $\varepsilon$ is an error term. The regression coefficient $\beta_{1}$ represents the returns to education, which indicates how much wage growth rate increases in response to an additional year of schooling and it is called Mincerian rate of return.

Control variables in standard Mincer equation is required, known as the extended Mincer equation, as there are other factors affect individuals' income in reality, such as gender, marital status, household registration of people and their province. Our extended Mincer equation specified as follows.

$$
\begin{aligned}
& \ln (\text { wage })=\beta_{0}+\beta_{1} e d u+\beta_{2} \exp +\beta_{3}(\exp )^{2}+\beta_{4} \text { male }+\beta_{5} \text { married }+ \\
& \beta_{6} \text { hukou }+\beta_{7} \text { job }+\beta_{8} \text { unit }+\beta_{9} P+\varepsilon
\end{aligned}
$$

Dummy variables 'male' represent gender (male $=1$, female $=0$ ); married is a dummy variable indicating marital status (married $=1$, unmarried $=0$ ); hukou is individual residence (urban $=1$, rural $=0)$; $\mathrm{P}$ is a dummy variable that present province.

\section{Data}

\subsection{Data source}

The data used in this paper is from China Health and Nutrition Survey (CHNS). The survey covered the urban and rural areas of China's eastern, central and western regions in twelve provinces (Liaoning, Heilongjiang, Shandong, Jiangsu, Henan, Hubei, Hunan, Guangxi, Guizhou, Beijing, Shanghai, Chongqing). Stratified cluster random sampling method was used in this survey, and the samples are representative for the country. The information about demographic characteristics, socioeconomic status, activities of daily living, body measurements are provided from the data set. Longitudinal data set currently available in 1989, 1991, 1993, 1997, 2000, 2004, 2006, 2009, 2011. CHNS data used in this paper has been published after correction by the University of North Carolina Population Center in 2013.

\subsection{Definition of disability}

Based on Xie's definition of disability [9] and this survey, disability declared via 3 identify questions as follow:

1) Whether respondents' activities of daily living is limited. In their daily activities: walking 200 meters, Climbing a few stairs without stopping, Squatting down, kneeling down, or bending over, Putting on your clothes, Bathing and eating by yourself, and so on. The options to answer these questions: a)no difficulty; b)have some difficulty, but can still do it; c) need help to do it; d)cannot do it at all. People choose $\mathrm{c}$ or $\mathrm{d}$ are defined as disabled.

2) There are some questions whether a person have any of these conditions: blindness in one eye, blindness in both eyes, loss of one arm or use of arm, loss of both arms or use of both arms, loss of one leg or use of one leg, loss of both legs or use of both legs in physical measurements survey. We define these respondents who choose "yes" as disabled. Of course, they are mainly visual and physical disabled persons. 
3) "Why are you not working" is one of the questions from this survey. "Disabled" is an option. Individuals who respond this option are included in the scope of persons with disabilities.

\subsection{Descriptive Statistics}

Table 1 shows the descriptive statistics of the variables used from 1991 to 2011. Data from 1989 was ignored, as the questions related to the definition of disability were not used in the questionnaire. Background demographic, work status, primary occupation and wages, education and daily activities data set were merged. In accordance with the definition of disability, there were 1659 pooled crosssectional data selected.

Wage based on personal net revenue after CPI (Consumer Price Index) adjustments in 2011. The regression sample limited to disabled non-students over the age of 16-60. The descriptive statistics of each variable is shown in Table 1 . From the comparison of disability and non-disability samples, the discrepancy of average annual net income is huge (about 4242 Yuan). In general, disabilities have low education, average 4.7 years but 7.8 years for non-disability. The status of education between disability and non-disability is demonstrated in figure 1. As we can see, generally speaking, the disabled has less education than non-disabled, the difference highlight from the data of female comparison, as the year of education from female disabled are 3.2, which is less than half compared to non-disabled woman. The proportion of disabilities with no schooling were more than $46 \%$ (Table 2), indicating that most of them not received formal education, and elementary school or less exceed $70 \%$, only about $10 \%$ have received high school and above education, less than $2 \%$ graduated from junior college and college/university and the proportion for non-disability is more than $5 \%$. The data indicate that the educational status of disabilities is worrying.

Table 1. Variable means for all, the disabled and non-disabled

\begin{tabular}{|c|c|c|c|}
\hline Variable name & all & disability & non-diaability \\
\hline Wage(Yuan) & 12773.50 & 8594.73 & 12836.72 \\
\hline Log wage & 8.92 & 8.66 & 8.92 \\
\hline Education years & 7.74 & 4.68 & 7.83 \\
\hline Experience(year) & 22.19 & 35.58 & 22.04 \\
\hline Male & 0.53 & 0.49 & 0.53 \\
\hline Married & 0.80 & 0.89 & 0.80 \\
\hline Hukou & 0.35 & 0.21 & 0.36 \\
\hline
\end{tabular}

Table 2. Educational status of disabled people (unit:\%)

\begin{tabular}{|c|c|c|c|}
\hline Educational Level & all & disability & non-diaability \\
\hline Never schooled & 17.79 & 46.72 & 16.99 \\
\hline Elementary school & 21.52 & 27.52 & 21.35 \\
\hline Junior middle school & 35.87 & 15.37 & 36.44 \\
\hline High school & 14.12 & 5.41 & 14.36 \\
\hline Professional middle school & 5.44 & 3.28 & 5.50 \\
\hline
\end{tabular}




\begin{tabular}{|c|c|c|c|}
\hline Junior college and college/university & 5.12 & 1.58 & 5.21 \\
\hline Graduate or above & 0.15 & 0.12 & 0.15 \\
\hline
\end{tabular}

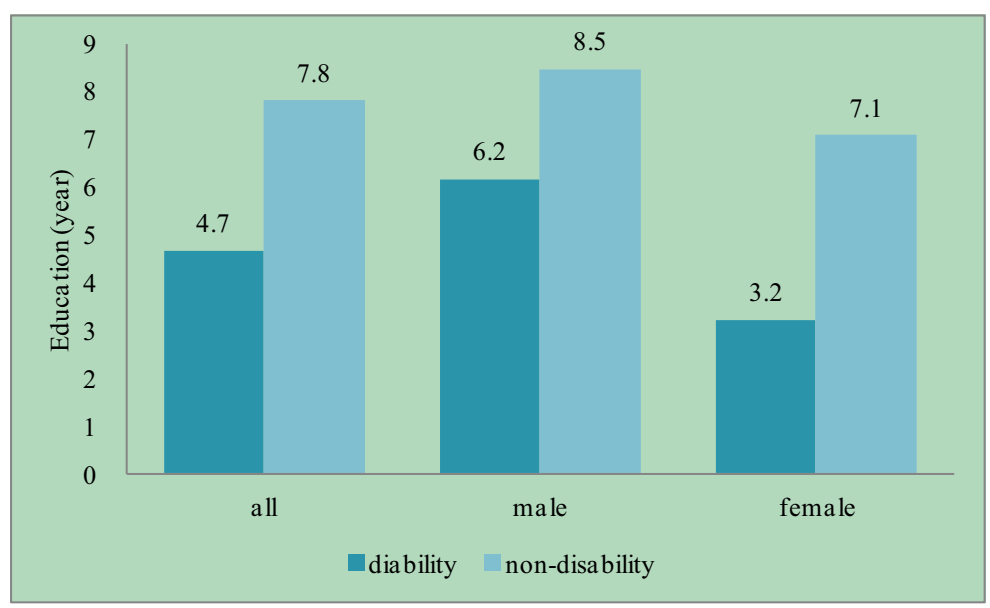

Figure 1. The status of education of the disabled and non-disabled

\section{Estimation results}

Simple Mincer equation was used to calculate returns to education of disabilities in China, the results shown in Table $38.4 \%$ was the rate of returns to education without other control variables. In comparison, the rate for non-disability is $12.5 \%$. Obviously, the former is less than the later. With adding the control variables of sex, marital status, household, the type of occupation and unit, province (all of the following regression results include dummy variable occupation, unit and province, but the corresponding regression coefficients are not listed in the tables for saving space), the rate of return to education of disabilities was $6.2 \%$. This means that for each additional year of education, the wage from disabilities will increase $6.2 \%$. Adjusted R-square rises to 0.305 , which is also shows the control variables have a great impact on the returns to education of disabilities. On the other hand, in regression for the non-disabled combine with control variables, the rate of return was $8.3 \%$, still higher than the disabilities. The overall rate of return to education was $8.1 \%$.

Table 3. Mincerian regression for all, the disabled and non-disabled people

\begin{tabular}{|c|c|c|c|}
\hline & all & disability & non-diaability \\
\hline eduyear & $0.124^{* * *}$ & $0.084^{* * *}$ & $0.125^{* * *}$ \\
\hline & $(0.002)$ & $(0.014)$ & $(0.002)$ \\
\hline $\exp$ & $0.047^{* * *}$ & 0.018 & $0.047^{* * *}$ \\
\hline & $(0.002)$ & $(0.033)$ & $(0.002)$ \\
\hline exp2 & $-0.053^{* * *}$ & 0.009 & $-0.051^{* * *}$ \\
\hline & $(0.005)$ & $(0.057)$ & $(0.005)$ \\
\hline cons & $7.020^{* * *}$ & $7.287^{* * *}$ & $(0.030)$ \\
\hline & $(0.030)$ & $(0.442)$ & 0.159 \\
\hline adj. $R^{2}$ & 0.158 & 0.153 & \\
\hline
\end{tabular}




\begin{tabular}{|c|c|c|c|}
\hline $\mathrm{F}$ & 1678.104 & 17.393 & 1679.340 \\
\hline$N$ & 26810 & 273 & 26537 \\
\hline
\end{tabular}

Standard errors in parentheses. $*$ significant at $10 \% ; * *$ significant at $5 \% ; * * *$ significant at $1 \%$.

Table 4. Extended mincerian regression

\begin{tabular}{|c|c|c|c|}
\hline & all & disability & non-diaability \\
\hline \multirow[t]{2}{*}{ eduyear } & $0.081^{* * *}$ & $0.062^{* * *}$ & $0.083^{* * *}$ \\
\hline & $(0.003)$ & $(0.018)$ & $(0.003)$ \\
\hline \multirow[t]{2}{*}{$\exp$} & $0.041^{* * *}$ & -0.007 & $0.040^{* * *}$ \\
\hline & $(0.003)$ & $(0.035)$ & $(0.003)$ \\
\hline \multirow[t]{2}{*}{$\exp 2$} & $-0.062^{* * *}$ & 0.029 & $-0.059^{* * *}$ \\
\hline & $(0.006)$ & $(0.061)$ & $(0.006)$ \\
\hline \multirow[t]{2}{*}{ male } & $0.234^{* * *}$ & $0.350^{* * *}$ & $0.233^{* * *}$ \\
\hline & $(0.013)$ & $(0.113)$ & $(0.013)$ \\
\hline \multirow[t]{2}{*}{ married } & -0.001 & $0.668^{* *}$ & -0.002 \\
\hline & $(0.021)$ & $(0.272)$ & $(0.021)$ \\
\hline \multirow[t]{3}{*}{ hukou } & -0.020 & -0.026 & -0.021 \\
\hline & $(0.016)$ & $(0.139)$ & $(0.016)$ \\
\hline & $(0.042)$ & (1.128) & $(0.043)$ \\
\hline occupation & yes & yes & yes \\
\hline unit & yes & yes & yes \\
\hline province & yes & yes & yes \\
\hline \multirow[t]{2}{*}{ _cons } & $8.376^{* * *}$ & $10.177^{* * *}$ & $8.362^{* * *}$ \\
\hline & $(0.061)$ & $(1.275)$ & $(0.061)$ \\
\hline $\operatorname{adj} \cdot R^{2}$ & 0.274 & 0.305 & 0.274 \\
\hline $\mathrm{F}$ & 287.141 & 5.618 & 284.594 \\
\hline$N$ & 19743 & 253 & 19490 \\
\hline
\end{tabular}

Standard errors in parentheses. $\quad *$ significant at $10 \%$; ** significant at $5 \%$; *** significant at $1 \%$.

Education is divided into several levels including no schooling, elementary, junior middle school and high school, professional middle school, junior college and college/university, graduate or above, no schooling as the reference group. The results (Table 5) showed that, compared to no schooling, for all and the non-disabled people returns to education were higher significantly in other educational level. However, for the disabled return to education is significantly higher than the return on high school, professional middle school and junior college and college/university and the extra return are 
$64.3 \%, 58 \%, 78.2 \%$ respectively. But in other educational level, the return is not significant compare to no schooling. The higher educational level, the higher of rate of returns to education they got, which is the same true for the disabled. In addition, the return to education for male is higher than that for female regardless of the disabled and non-disabled.

Table 5. Regression in different educational level

\begin{tabular}{|c|c|c|c|}
\hline & all & disability & non-disability \\
\hline \multirow[t]{2}{*}{ Elementary school } & $0.085^{* *}$ & 0.131 & $0.086^{* *}$ \\
\hline & $(0.036)$ & $(0.246)$ & $(0.037)$ \\
\hline \multirow[t]{2}{*}{ Junior middle school } & $0.233^{* * *}$ & 0.254 & $0.239^{* * *}$ \\
\hline & $(0.035)$ & $(0.232)$ & $(0.035)$ \\
\hline \multirow[t]{2}{*}{ High school } & $0.390^{* * *}$ & $0.643^{* * *}$ & $0.395^{* * *}$ \\
\hline & $(0.037)$ & $(0.247)$ & $(0.037)$ \\
\hline \multirow[t]{2}{*}{ Professional middle school } & $0.672^{* * *}$ & $0.580^{* *}$ & $0.683^{* * *}$ \\
\hline & $(0.040)$ & $(0.265)$ & $(0.040)$ \\
\hline \multirow[t]{2}{*}{ Junior college and college/university } & $1.065^{* * *}$ & $0.782^{* * *}$ & $1.077^{* * *}$ \\
\hline & $(0.042)$ & $(0.287)$ & $(0.042)$ \\
\hline \multirow[t]{2}{*}{ Graduate or above } & $1.432^{* * *}$ & 0.328 & $1.486^{* * *}$ \\
\hline & $(0.108)$ & $(0.576)$ & $(0.110)$ \\
\hline \multirow[t]{2}{*}{$\exp$} & $0.047^{* * *}$ & -0.001 & $0.047^{* * *}$ \\
\hline & $(0.003)$ & $(0.037)$ & $(0.003)$ \\
\hline \multirow[t]{2}{*}{$\exp 2$} & $-0.077^{* * *}$ & 0.018 & $-0.075^{* * *}$ \\
\hline & $(0.006)$ & $(0.063)$ & $(0.006)$ \\
\hline \multirow[t]{2}{*}{ male } & $0.257^{* * *}$ & $0.369^{* * *}$ & $0.256^{* * *}$ \\
\hline & $(0.013)$ & $(0.113)$ & $(0.013)$ \\
\hline \multirow[t]{2}{*}{ married } & -0.009 & $0.681^{* *}$ & -0.011 \\
\hline & $(0.021)$ & $(0.276)$ & $(0.021)$ \\
\hline \multirow[t]{2}{*}{ hukou } & $-0.034^{* *}$ & -0.074 & $-0.034^{* *}$ \\
\hline & $(0.016)$ & $(0.145)$ & $(0.016)$ \\
\hline occupation & yes & yes & yes \\
\hline unit & yes & yes & yes \\
\hline province & yes & yes & yes \\
\hline \multirow[t]{2}{*}{ _cons } & $8.552^{* * *}$ & $10.450^{* * *}$ & $8.541^{* * *}$ \\
\hline & $(0.062)$ & $(1.277)$ & $(0.062)$ \\
\hline adj. $R^{2}$ & 0.289 & 0.301 & 0.290 \\
\hline $\mathrm{F}$ & 259.618 & 4.743 & 257.405 \\
\hline$N$ & 19743 & 253 & 19490 \\
\hline
\end{tabular}


Standard errors in parentheses. * significant at 10\%; ** significant at 5\%;*** significant at $1 \%$.

Education of the disabled and their income is closely relative. In China, average years of education of disabled people are very low, which has negative effect on their income increases. Persons with disabilities always requires special needs, their spending in medicinal, health care, life are higher compared to non-disabled. If people with disabilities fell into a circle of "poor education - low income - poverty - disease", that will increase the influence of disability on themselves and their family. Therefore improvement in the overall educational status of the disabled to increase their income is fundamental measures to alleviate the disadvantageous consequences caused by disabilities. At this stage, the most important is to increase effective supply of special education, such as establishment of more schools for the handicapped, training of special education teachers and encourage persons with disabilities into the school. The policy makers should pay more attention to the more vulnerable groups in the disability groups. The disabled female is the weakest of the weak group, and they need more help from public and government.

\section{Conclusions}

This paper suggested as follow: First, the return to education of the disabled is less than non-disabled whether we use simple Mincerian regression or extended regression. In addition, from the regression in different education we can conclude that the higher rate of returns to education towards to increasing level of education for the disabled, whereas in the lower education level such as elementary school and junior middle school, this trend is not obvious. Finally, disabled men have better advantage than disabled women at return to education. It is the same for the non-disabled people.

Current study shows that returns to education of persons with disabilities has been ignored for many years, few Chinese scholars involved in this research area. Although a multi-level analysis of the returns to education of persons with disabilities was presented in this paper, but the analysis is not far enough to understand educational status of the disabled. Firstly, the definition of disability according to the CHNS data of features, it cannot contain all type of persons with disabilities, such as mental, intellectual, speech and hearing disabilities. Secondly, although the CHNS data covers over 20 years from 1989 to 2011 , there is still limit data from each wave to display the trend of returns to education. Therefore, more data required on the survey of disabilities in public to support researchers for further studies. We also would like to call on scholars engaged in the study of persons with disabilities to promote the development of the disabled.

\section{Acknowledgment}

This research is funded by Chinese National Social Sciences (GN:11CJY026).

\section{References}

1. http://www.cdpf.org.cn/sytj/content/2007-11/21/content_30316035_3.htm

2. K. Hollenbeck and J. Kimmel, Differences in the Returns to Education for Males by Disability Status and Age of Disability Onset, Southern Economic Journal, 2008(3):707-724

3. K. Hollenbeck, J. Kimmel, The Returns to Education and Basic Skills Training for Individuals with Poor Health or Disability, Upjohn Institute Staff Working Paper No. 01-72, 2001.

4. K. Lamichhane and Y. Sawada, Disability and Returns to Education in a Developing Country, CIRJE Discussion Paper No.CIRJE-F-645, 2009.

5. S. Li and S. Ding, Long-term Change in Private Returns to Education in Urban China, Social Sciences in China, 2003(6):58-72.

6. L.T. Zhao, Rising Returns to Education in Rural China, Social Sciences in China, 2006(3):98-109 
7. D.H. Meng, L.F. Su and D.S. Lai, An Empirical Study on the Returns to Education of the Ethnic Minorities in Chinese Cities and Towns in the Economic Transition Period, Ethno-National Studies, 2012(1):25-34.

8. J. Mincer, Education, experience and earnings. New York: Columbia University Press, 1974.

9. E. Xie, Disability and Labor market, Management World, 2011(4): 37-45. 